\title{
Stigmatization and self-perception in children with atopic dermatitis
}

\section{Pavel V Chernyshov}

Department of Dermatology and Venereology, National Medical University, Kiev, Ukraine
Correspondence: Pavel V Chernyshov Department of Dermatology and Venereology, National Medical University, Bulvar Shevchenko, 13, Kiev 0160I, Ukraine

Tel +380442348660

Fax +380 442348660

Email chernyshovpavel@ukr.net
This article was published in the following Dove Press journal:

Clinical, Cosmetic and Investigational Dermatology

21 July 2016

Number of times this article has been viewed

Abstract: Atopic dermatitis (AD) is one of the most common skin diseases. Prevalence of $\mathrm{AD}$ is highest in childhood. Because of chronicity and often visible lesions, AD may lead to stigmatization and problems with self-perception. However, problems of self-perception and stigmatization in $\mathrm{AD}$ children are poorly studied. Literature data on general tendencies of children's development, clinical course, and epidemiologic tendencies of AD in different age groups make it possible to highlight three main periods in the formation of self-perception and stigmatization. The first period is from early infancy till 3 years of age. The child's problems in this period depend on parental exhaustion, emotional distress, and security of the mother-child attachment. The child's AD may form a kind of vicious circle in which severe AD causes parental distress and exhaustion that in turn lead to exacerbation of AD and psychological problems in children. The second period is from 3 till 10 years of age. During this period, development of $\mathrm{AD}$ children may be influenced by teasing, bullying, and avoiding by their peers. However, the majority of children in this age group are very optimistic. The third period is from 10 years till adulthood. Problems related to low self-esteem are characteristic during this period. It is important to identify children with $\mathrm{AD}$ and their parents who need psychological help and provide them with needs-based consultation and care. Appropriate treatment, medical consultations, and educational programs may help to reduce emotional problems in AD children and their parents. Keywords: atopic dermatitis, stigmatization, self-perception, quality of life, children, pediatric dermatology, skin disease

\section{Introduction}

Atopic dermatitis (AD) is one of the most common skin diseases that affects up to one-fifth of children. AD is often the first step in the development of other atopic diseases. The European Task Force on AD defines atopy as the familial tendency to develop Th2 responses against common environmental antigens, which involves both immunoglobulin E-associated, extrinsic, and nonimmunoglobulin E-associated, intrinsic, subtypes. AD has a strong genetic and immunologic background characterized by exacerbations and remissions that need multidisciplinary and varied treatment strategies. Majority of cases with AD can be regarded as "mild", with $10 \%-20 \%$ of patients suffering from severe skin lesions; this percentage seems to be higher in the adult $\mathrm{AD}$ population. ${ }^{1-7}$ Majority of $\mathrm{AD}$ patients have a positive family history of atopic diseases. ${ }^{8} \mathrm{AD}$ is a common condition in first years of life but disappears in almost a half of children by 3 years of age. ${ }^{9}$ 
The marked increase of AD in "developed" countries since the second half of the 20th century caused significant socioeconomic impact. ${ }^{10}$ Nowadays, AD has a significant direct and indirect financial burden for health care systems and the patients' families. ${ }^{11,12}$ A substantial number of AD patients had abstained from a specific education or a job due to $\mathrm{AD} \cdot{ }^{13} \mathrm{AD}$ has a great influence on quality of life (QoL) because of its chronic character and the not-easy-to-resist pruritus, and consequently sleeplessness and family impact ${ }^{14}$ may lead to parental anxiety. ${ }^{15}$

Clinical manifestations of many skin diseases are potentially discriminating. ${ }^{16,17}$ Individuals with lesions on highly visible sites of the skin are at a higher risk of discrimination. Disease-related stigmatization is a common problem in children with skin conditions ${ }^{18,19}$ and should not be ignored.

Stigmatization (in dermatology) - defined as a process in which skin appearance is negatively judged and persons who are affected experience absence of acceptance because of their visible symptoms - may have profound consequences in the life of patients, such as increased anxiety or social avoidance. $^{20}$

It was shown that negative children's attitudes toward individuals with stigma are present in children as young as 3 years of age. ${ }^{21}$ Thus, it is possible to hypothesize that stigmatization and negative changes of self-perception in children with AD may start after this age. However, results of published studies in this field showed that even in the youngest age group of children, affected relationship within the mother-child dyad may lead to problems with stigmatization and self-perception in future life. A meta-analytic review confirmed associations between mothers' depression and multiple domains of children's emotional and behavioral problems. These problems showed negative correlation with the age of children. ${ }^{22}$ It is possible to speculate that this negative correlation with age may be explained by lower level of mother-child attachment in older children. Cohn et $\mathrm{al}^{23}$ showed that depression has negative effect on mother-child behavior. This effect may vary with development, chronicity, and presence of other risk factors.

Mothers of AD infants described themselves as more depressive/hopeless, anxious/overprotective, and characterized their infant as less frequently positive and more frequently negative in its emotional behavior compared to controls. ${ }^{24}$ In contrast, mental distress in mothers of schoolaged children with $\mathrm{AD}$ was not higher than in controls. ${ }^{25}$ In the study on family QoL by Lawson et al, ${ }^{15}$ majority of parents of AD children reported exhaustion, frustration, guilt, resentment, and helplessness. In the same study, anxiety of
AD parents was related to child's problems at school. Meanwhile, maternal depression in the study by Goodman et $\mathrm{al}^{26}$ was related to children having been rated by their teachers as less popular.

Negative cognitions about the self in children may be related to maternal depression and chronic stress and to the quality of perceived and actual interactions with the mother. ${ }^{27}$ Finally, even electroencephalogram activity results are different in infants of depressed and nondepressed mothers. ${ }^{28}$

Some researchers speculate that AD-induced inflammation from the early age may lead to changes in skin sensation, altering sensory perception and communication that subsequently may cause problems related to emotional development. Meanwhile, it looks like haptic communication with parents is crucial not only for normal development of a child but is also important for the parents and serves to improve their attachment. ${ }^{29}$ Behavioral problems and parental distress are important features of severe $\mathrm{AD}$ in early childhood. However, it was reported that AD does not diminish the security of the mother-child attachment. ${ }^{30}$

As mentioned earlier, negative children's attitudes toward individuals with stigma are present in children as young as 3 years of age. ${ }^{31}$ Until this age, AD disappears in a significant proportion of children, ${ }^{9}$ decreasing the number of those who may be stigmatized because of their skin condition. However, Magin et $\mathrm{a}^{32}$ in their article on teasing and bullying in AD, psoriasis, and acne presented reminiscence of the patient who had experience of teasing by older children:

I remember one instance a much older girl came up to me, she was trying to show her friends, and sort of picking on me, bullying me into showing her friends.

Level of stigmatization has been reported to be associated with AD severity. ${ }^{33}$ Majority of AD children have mild course of disease, and it was reported that not more than one-fifth of children with $\mathrm{AD}$ suffer from severe eczematous skin lesions ${ }^{34}$ and potentially are at a high risk of stigmatization. However, because AD is one of the most common skin diseases in childhood, ${ }^{35}$ even a minor proportion of patients with AD results in a high absolute number. Thus, psychological disturbance rates in children with moderate and severe $\mathrm{AD}$ are significantly higher than in controls. ${ }^{25}$ Meanwhile, in the study on QoL, it was reported that AD severity (SCORAD scoring of AD) significantly correlated with all items of ADspecific questionnaire except the item "how much trouble have you had because of your skin with other people calling you names, teasing, bullying, asking questions or avoiding you" in Czech children. ${ }^{12}$ 
Ring $^{36}$ in his recent book described several aspects of stigmatization of AD children: "Adults admonitions like "Stop scratching yourself once and for all!" leads to additional isolation. Reflexes which associate any skin disease with contagion are still prevalent. Young people may be stigmatized when their skin is not "smooth and pure", as can be seen on TV".

AD patients confirmed these statements by personal experience: "Students can be a bit nasty, I just felt like a bit of a freak, one kid told me once I was a leper, that wasn't very nice [and I felt] disgusting, like as if I didn't already feel like a total freak anyway."32

Bullying is not considered as an exact synonym to aggression and may include physical and verbal components, but may not include social exclusion. Meanwhile, the process of bullying in children of school age may be slightly different from the definitional concept broadly used in scientific literature. It may be partially explained by the fact that the classic definition of bullying still does not fully include social exclusion. ${ }^{37}$ Bullying involves "harmdoing" that is carried out repeatedly, over time, and within a relationship, involving a power imbalance between the bully and the bullied. Being bullied may have considerable adverse consequences, including psychological or psychiatric harm. ${ }^{38}$

Formation of self-perception in AD children may in some aspects vary from their peers. In most cases, preschool children are very optimistic. In contrast, older children are more pessimistic, and correlation of their self-perception and their actual performance is much higher. Biological transformations in adolescents are characterized by many changes at different levels. The role of social relations with peers in this age group is growing significantly. ${ }^{39} \mathrm{~A}$ negative perception of one's body image has the effect of lowering self-esteem, which in turn increases psychological distress. ${ }^{40}$ Both negative perception of body image by peers and self-perception of patient with AD may be aggravated in adolescents.

AD may affect social maturation of teenagers and their school studies. The choice of future specialty may also be influenced by $\mathrm{AD}$, and many factors should be estimated to make a right choice..$^{41}$ During primary and secondary school, patients with severe AD in childhood had a lower number of friends, and a lower percentage of children spent their leisure time with their friends. AD children less often belonged to a group of friends and more rarely participated in social events during secondary school than patients with moderate $\mathrm{AD}$ and, in comparison with non-AD children of the same age, less often reported to have been member of a sports club during their primary and secondary school period. ${ }^{42}$

A population-based study ${ }^{43}$ found a significant association between mental distress and AD in adolescents. In females, elder students with AD reported more mental distress than younger ones. Meanwhile, there was no correlation of mental distress with the age of male AD students. The tendency that levels of mental distress increase with patients' age was also reported in students with other diseases and healthy controls. Nonetheless, conditions other than AD had more severe impact on students' distress. ${ }^{43}$ The majority of AD schoolchildren and adolescents had episodes of AD-related shame. Many adolescents with AD also avoided going in for sports and socialization. Missing classes and doing things on their own were typical for adolescents with AD. ${ }^{42}$ School-aged children with moderate and severe AD are at high risk of developing psychological difficulties, which may have implications for their academic and social development. ${ }^{25}$

Skin diseases should be measured not only by symptoms, but also by physical, psychological, and social parameters. ${ }^{29}$ Health-related QoL (HRQoL) instruments may help to assess these parameters. Majority of the studies on HRQoL in pediatric dermatology are dedicated to AD. Most of the disease-specific HRQoL instruments created especially for children with skin diseases are AD specific. ${ }^{44}$ Results on how $\mathrm{AD}$ affects children's friendships, self-consciousness, and social life and leads to teasing and bullying according to their self-assessment by means of the Children Dermatology Life Quality Index (CDLQI) ${ }^{45}$ in different studies ${ }^{12,46-52}$ are presented in Table 1.

Slattery et $\mathrm{a}^{53}$ showed that the impact of AD on HRQoL of adolescents was associated with sleep loss and depressive symptoms. The authors suggest that chronic sleep loss increases emotional and physical fatigue and alters social functioning. Chronic impairment of principal aspects of adolescents' QoL, including relations with peers, may lead to depressive symptoms.

Two important aspects of positive mental health are selfesteem (evaluative attitude toward the self) and life satisfaction (a global judgment of one's life). Low self-esteem and low life satisfaction are associated with poorer academic achievement and anxiety, depression, and eating pathology. Research suggests that adolescents will have worse health outcomes when they perceive their family to be lower in the socioeconomic hierarchy compared with families of peers. It was shown that low family income was associated with lower 
Table I How AD affects children's friendships, self-consciousness, and social life and leads to teasing and bullying according to the CDLQI results (each CDLQI question is answered on a four-point Likert scale scored from 0 to $3^{45}$ ) in different studies. ${ }^{12,46-52}$

\begin{tabular}{|c|c|c|c|c|c|c|c|c|c|c|c|}
\hline CDLQI items & Singapore ${ }^{12}$ & $\begin{array}{l}\text { Czech } \\
\text { Republic }^{\prime 2}\end{array}$ & Italy ${ }^{12}$ & Ukraine $^{12}$ & UK $^{46}$ & Malaysia $^{47}$ & UK $^{48}$ & Sweden ${ }^{49}$ & Korea $^{50}$ & Turkey ${ }^{51}$ & $\operatorname{Iran}^{52}$ \\
\hline $\begin{array}{l}\text { How embarrassed } \\
\text { or self-conscious, } \\
\text { upset, or sad have } \\
\text { you been because } \\
\text { of your skin? }\end{array}$ & $0.89 \pm 0.87$ & $1.18 \pm 0.98$ & $0.66 \pm 0.94$ & $1.23 \pm 1.10$ & $1.2^{\mathrm{a}}$ & $1.1^{\mathrm{a}}$ & $0.4^{\mathrm{a}}$ & $0.86 \pm 0.93$ & $0.9 \pm 0.9$ & $1.00 \pm 1.03$ & $2.4^{\mathrm{a}}$ \\
\hline $\begin{array}{l}\text { How much has } \\
\text { your skin affected } \\
\text { your friendships? }\end{array}$ & $0.57 \pm 0.65$ & $0.30 \pm 0.65$ & $0.26 \pm 0.60$ & $0.80 \pm 0.95$ & $0.3^{\mathrm{a}}$ & $0.8^{\mathrm{a}}$ & $0.2^{\mathrm{a}}$ & NA & $0.5 \pm 0.8$ & $0.58 \pm 0.83$ & $2.7^{\mathrm{a}}$ \\
\hline $\begin{array}{l}\text { How much has } \\
\text { your skin trouble } \\
\text { affected going out, } \\
\text { playing, or doing } \\
\text { hobbies? }\end{array}$ & $1.06 \pm 1.00$ & $0.72 \pm 0.95$ & $0.24 \pm 0.71$ & $1.16 \pm 1.06$ & $0.8^{\mathrm{a}}$ & $1.0^{\mathrm{a}}$ & $0.5^{\mathrm{a}}$ & NA & $0.6 \pm 0.8$ & $0.56 \pm 0.78$ & $2.4^{\mathrm{a}}$ \\
\hline $\begin{array}{l}\text { How much trouble } \\
\text { have you had } \\
\text { because of your } \\
\text { skin with other } \\
\text { people calling you } \\
\text { names, teasing, } \\
\text { bullying, asking } \\
\text { questions, or } \\
\text { avoiding you? }\end{array}$ & $1.17 \pm 0.87$ & $0.44 \pm 0.64$ & $0.32 \pm 0.77$ & $0.95 \pm 0.91$ & $0.3^{\mathrm{a}}$ & $1.6^{\mathrm{a}}$ & $0.3^{\mathrm{a}}$ & NA & $0.4 \pm 0.7$ & $0.16 \pm 0.54$ & $2.2^{\mathrm{a}}$ \\
\hline
\end{tabular}

Note: ${ }^{a}$ Numeric data were adopted from figure and are approximate values. Data are presented as mean \pm standard deviation.

Abbreviations: AD, atopic dermatitis; CDLQI, Children Dermatology Life Quality Index; NA, not available.

self-esteem and life satisfaction in a representative sample of 11-year-olds from the UK. After adjustment for income, young people who perceived their family to be poorer than their peers had lower self-esteem and life satisfaction. Those who perceived their family to be richer than their peers also had worse self-esteem and life satisfaction. ${ }^{54}$ It was also reported that low socioeconomic status associated with a higher frequency of disturbed sleep due to AD in children. In contrast, no significant association was observed between socioeconomic status and frequency of disturbed sleep due to either asthma or rhinitis. ${ }^{55}$

In those children who cannot measure their QoL by themselves, proxy instruments should be used instead of self-assessment. Development of proxy AD-specific HRQoL instrument showed that problems of self-esteem, teasing, and social acceptance do not play a significant role in the life of majority of young AD children according to their parents' point of view. ${ }^{56}$ Meanwhile, AD frequently causes mood changes in young children..$^{57,58}$ Despite the possibility of imperfect agreement between self-report and proxy-report, Ricci et $\mathrm{a}^{59}$ showed that parents perceive their child's mood with great sensitivity and attention and are able to sense small alterations and changes in the child's mood. In most cases, the person who fills in the proxy questionnaires is mother.
However, it is better to collect results of both parents because each spouse could have alternative view. ${ }^{60}$ To avoid the problem of imperfect agreement between parental assessment of child's QoL and self-assessed QoL, the European Academy of Dermatology and Venereology Task Force on QoL recommends to obtain information from both children and parents whenever possible and to use proxy-rating results as a single measure only in the youngest age group. ${ }^{10}$

Scores for the AD-specific Infants' Dermatitis QoL Index (IDQoL) item for impact on the "child's mood" showed a significant difference among the sexes in children matched by age and $\mathrm{AD}$ severity. The mood of young girls with $\mathrm{AD}$ was more affected according to proxy assessment by their parents. ${ }^{61}$ Chronically altered mood may influence formation of low self-esteem and lead to stigmatization in future. The impact of $\mathrm{AD}$ on the mood of young children according to proxy-rating results is presented in Table 2 .

It was shown by the results of proxy HRQoL assessment that in some countries, parents consider AD to be more severe in older group of children. The reason for that can be due to more serious self-consciousness and stress connected with psychological and physical limitations caused by AD in older children. ${ }^{58} \mathrm{~A}$ recent international study on self-assessment HRQoL in children with AD revealed that the item "how 
Table 2 The impact of $A D$ on the mood of young children according to the IDQoL results (each IDQoL question is answered on a four-point Likert scale scored from 0 to $3^{57}$ ) from different studies ${ }^{49,57,58,60,67,76-78}$

\begin{tabular}{ll}
\hline Country & Impact of AD on child's mood \\
\hline UK $^{57}$ & $1.10 \pm 0.99$ \\
Sweden $^{49}$ & $1.00 \pm 0.86$ \\
Saudi Arabia $^{76}$ & $1.84 \pm 0.65$ \\
Serbia $^{77}$ & $1.93 \pm 0.82$ \\
Finland $^{78}$ & $0.3^{\mathrm{a}}$ \\
The Netherlands $^{58}$ & $0.51 \pm 0.65$ \\
Brazil $^{58}$ & $1.07 \pm 0.70$ \\
Korea $^{58}$ & $1.02 \pm 0.90$ \\
Czech Republic $^{67}$ & $0.7^{\mathrm{a}}$ \\
Ukraine $^{60}$ & $0.85 \pm 0.49$ \\
\hline
\end{tabular}

Note: aNumeric data were adopted from figure and are approximate values. Abbreviations: AD, atopic dermatitis; IDQoL, Infants' Dermatitis Quality of Life Index.

much trouble have you had because of your skin with other people calling you names, teasing, bullying, asking questions or avoiding you" was assessed to be quite high only by children from Singapore. Meanwhile, the item "how much has your skin affected your friendships" was one of the lowest scored items in all four countries. ${ }^{12}$

Results of the self-assessment of HRQoL in AD children showed that girls were significantly more embarrassed, selfconscious, upset, or sad because of their skin disease. Meanwhile, both girls and boys with AD did not feel that AD had a high impact on their friendships and did not report teasing, bullying, avoiding, and calling names as a major problem. The fact that this item was one of the lowest scored item and had poorly correlated with SCORAD in girls indicates that the impact of $\mathrm{AD}$ on many aspects of girls' life is growing together with SCORAD mostly because of their impaired self-perception. Thus, the tendency of social avoidance is higher in patients with more severe signs. Meanwhile, psychological problems increase together with disease severity in both sexes; girls in general need more attention to their AD-related psychological problems. Prevention of such avoiding behavior in girls with more severe AD and elder adolescent girls in the case of absence of teasing and bullying is an important task. Progression of such behavior may affect different aspects of everyday life in elder girls and may lead to even more serious consequences in their future life. ${ }^{62}$ Another study showed that bullying at school among 15-year-olds has been associated with AD in boys but not in girls. ${ }^{63}$

AD has significant secondary impact on patient's family. Family QoL assessment of parents of young children with $\mathrm{AD}$ revealed high levels of tiredness, exhaustion, and emotional distress. ${ }^{58}$ Meanwhile, impact on personal relations was the lowest scored item in the study on dermatology-specific family QoL instrument. ${ }^{64}$

It is likely that the presence of $\mathrm{AD}$ lesions on the visible parts of girls' skin causes more problems for parents than equivalent lesions on boys' skin because they think it is more important for girls to have healthy looking facial skin. More parents of girls were found to be distressed, and this type of distress may influence their child's mood directly or impact the parent's assessment of the child's mood. Higher age in the child and thus longer duration of $\mathrm{AD}$ was associated with an increase in emotional distress in parents, irrespective of the patient's sex, but only in the girls' group did higher age have severe impact on family relations. ${ }^{61}$ Parental divorce or separation may be a severe consequence of the chronic impact of daughter's $\mathrm{AD}$ on family relationships. Meanwhile, parental divorce and separation were reported to be associated with higher incidence of $A D$ in children ${ }^{65}$ However, Walker et a ${ }^{66}$ did not find differences in parental stress levels, stability of marriages, and involvement of father with child between parents of AD children and parents of healthy 7-12-year-old children. ${ }^{66}$

Literature data on general tendencies of children's development, clinical course, and epidemiologic tendencies of $\mathrm{AD}$ in different age groups make it possible to highlight three main periods in the formation of self-perception and stigmatization. The first period is from early infancy till 3 years of age. The child's problems in this period depend on parental exhaustion, emotional distress, and security of the mother-child attachment. The child's AD may form a kind of vicious circle in which severe AD causes parental distress and exhaustion that in turn lead to exacerbation of $\mathrm{AD}$ and psychological problems in their children. Negative children's attitude toward individuals with stigma is, probably, absent in this age group. ${ }^{21}$ The second period is from 3 till 10 years of age. During this period, development of AD children may be influenced by teasing, bullying, and avoiding by their peers. However, majority of children in this age group are very optimistic. ${ }^{39}$ One study showed that parental assessment of their child's mood did not differ between $\mathrm{AD}$ and non-AD children from 7 till 12 years of age ${ }^{66}$ In contrast, mood changes of the child is one of the most common complaints in parents of young AD children. ${ }^{58,67}$ The third period starts after 10 years of age when children become more pessimistic and critical to themselves. Problems related to low self-esteem and avoidance are characteristic for this period.

Governments, nongovernmental organizations, and health institutions in many countries have launched campaigns to 
reduce stigma related to illness. ${ }^{68}$ High prevalence of AD in children is an argument to implement basic data on this condition into school programs. I especially avoided to mention exact subjects from the school program because it may significantly vary between countries: biology, basics of health care, etc. In particular, such programs should clearly state that $\mathrm{AD}$ is not an infection and contagious condition. This may decrease several aspects of stigmatization.

Training programs developed to prevent distress and helplessness of the parents and for more effective management of childhood AD include sessions with psychologists on stress management. ${ }^{69,70}$ Self-assessment of children with AD showed improvement of personal relationship after joining support group. ${ }^{71}$ In mothers of children with $\mathrm{AD}$, anxiety and depression levels decreased to within the range of normal values as reported in a control group after six 90-minute educational sessions. ${ }^{72}$ Grillo et al ${ }^{73}$ reported that school-age AD children learned in a different way from parents/caregivers who were responsible for care and management of an infant's AD, and some children in this age group needed further motivation and negotiation to practice self-management. A minor proportion of $\mathrm{AD}$ patients and their parents need psychological help. It was shown that only $8 \%$ of families of preschool AD children were interested in psychological items during educational program. ${ }^{71}$ However, it is important to identify these people during consultations and through patient organization facilities because their problems may have severe consequences.

Appropriate treatment approaches that can decrease skin lesions, itching, and sleep problems in AD children are extremely important. Resolving of highly visible lesions should lead to reduction of various aspects of stigmatization and improvement of self-perception. Meanwhile, better sleep quality may decrease levels of stress and exhaustion in patients and their parents. Clinical trial results showed that effective topical treatment of children with AD was associated with improvement of their self-consciousness, ${ }^{74}$ parental psychosomatic well-being, and emotional coping of parents. ${ }^{75}$

\section{Conclusion}

Despite a high prevalence of $\mathrm{AD}$, its influence on stigmatization and self-perception in children is poorly studied. Analysis of available literature showed that problems of self-perception and stigmatization do not play a key role in majority of $\mathrm{AD}$ children. However, even a minor proportion of patients with $\mathrm{AD}$ result in a high absolute number. It is important to identify such patients and provide them with needs-based consultation and care. AD in a child may lead to exhaustion, emotional distress, and depressive symptoms in parents. These parental problems may subsequently cause difficulties with self-perception and stigmatization of their children by other people and exacerbation of AD signs.

\section{Disclosure}

The author reports no conflict of interests in this work.

\section{References}

1. Wollenberg A, Oranje A, Deleuran M et al. ETFAD/EADV Eczema task force 2015 position paper on diagnosis and treatment of atopic dermatitis in adult and paediatric patients. $J$ Eur Acad Dermatol Venereol. 2016;30(5):729-747.

2. Ring J, Alomar A, Bieber T, et al. Guidelines for treatment of atopic eczema (atopic dermatitis) part I. J Eur Acad Dermatol Venereol. 2012;26(8): 1045-1060.

3. DaVeiga SP. Epidemiology of atopic dermatitis: a review. Allergy Asthma Proc. 2012;33(3):227-234.

4. Oranje AP. Evidence-based pharmacological treatment of atopic dermatitis: an expert opinion and new expectations. Indian J Dermatol. 2014; 59(2):140-142.

5. Darsow U, Wollenberg A, Simon D, et al. European Task Force on Atopic Dermatitis/EADV Eczema Task Force. Difficult to control atopic dermatitis. World Allergy Organ J. 2013;6(1):1-6.

6. Janmohamed SR, Oranje AP, Devillers AC, et al. The proactive wet-wrap method with diluted corticosteroids versus emollients in children with atopic dermatitis: a prospective, randomized, double-blind, placebocontrolled trial. J Am Acad Dermatol. 2014;70(6):1076-1082.

7. Chernyshov PV. Randomized, placebo-controlled trial on clinical and immunologic effects of probiotic containing Lactobacillus rhamnosus R0011 and L. helveticus R0052 in infants with atopic dermatitis. Microb Ecol Health Dis. 2009;21(3-4):228-232.

8. Eichenfield LF, Tom WL, Chamlin SL, et al. Guidelines of care for the management of atopic dermatitis: section 1. Diagnosis and assessment of atopic dermatitis. J Am Acad Dermatol. 2014;70(2):338-351.

9. Illi S, von Mutius E, Lau S, et al. The natural course of atopic dermatitis from birth to age 7 years and the association with asthma. $J$ Allergy Clin Immunol. 2004;113(5):925-931.

10. Chernyshov P, de Korte J, Tomas-Aragones L, Lewis-Jones S. EADV taskforce's recommendations on measurement of health-related quality of life in paediatric dermatology. $J$ Eur Acad Dermatol Venereol. 2015;29(12):2306-2316.

11. Mancini AJ, Kaulback K, Chamlin SL. The socioeconomic impact of atopic dermatitis in the United States: a systematic review. Pediatr Dermatol. 2008;25(1):1-6.

12. Chernyshov P, Ho R, Monti F, et al. An international multi-center study on self-assessed and family quality of life in children with atopic dermatitis. Acta Dermatovenerol Croat. 2015;23(4):247-253.

13. Holm EA, Esmann S, Jemec GB. The handicap caused by atopic dermatitis - sick leave and job avoidance. J Eur Acad Dermatol Venereol. 2006;20(3):255-259.

14. Lewis-Jones S. Quality of life and childhood atopic dermatitis: the misery of living with childhood eczema. Int J Clin Pract. 2006;60(8):984-992.

15. Lawson V, Lewis-Jones MS, Finlay AY, Reid P, Owens RG. The family impact of childhood atopic dermatitis: the Dermatitis Family Impact questionnaire. Br J Dermatol. 1998;138(1):107-113.

16. Bewley A, Burrage DM, Ersser SJ, Hansen M, Ward C. Identifying individual psychosocial and adherence support needs in patients with psoriasis: a multinational two-stage qualitative and quantitative study. J Eur Acad Dermatol Venereol. 2014;28(6):763-770.

17. Ajose FO, Parker RA, Merrall EL, Adewuya AO, Zachariah MP. Quantification and comparison of psychiatric distress in African patients with albinism and vitiligo: a 5-year prospective study. J Eur Acad Dermatol Venereol. 2014;28(7):925-932.

18. Krüger C, Panske A, Schallreuter KU. Disease-related behavioral patterns and experiences affect quality of life in children and adolescents with vitiligo. Int J Dermatol. 2014;53(1):43-50. 
19. de Jager ME, De Jong EM, Evers AW, Van De Kerkhof PC, Seyger MM. The burden of childhood psoriasis. Pediatr Dermatol. 2011;28(6): 736-737.

20. Schmid-Ott G, Steen T. Skin disorders and quality of life. In: JH Stone, M Blouin, editors. International Encyclopedia of Rehabilitation. 2010. Available from: http://cirrie.buffalo.edu/encyclopedia/en/article/152/. Accessed June 17, 2016.

21. Cramer P, Steinwert T. Thin is good, fat is bad: how early does it begin? J Appl Dev Psychol. 1998;19(3):429-451.

22. Lovejoy MC, Graczyk PA, O’Hare E, Neuman G. Maternal depression and parenting behaviour: a meta-analytic review. Clin Psychol Rev. 2000;20(5):561-592.

23. Cohn JF, Campbell SB, Matias R, Hopkins J. Face-to-face interactions of postpartum depressed and nondepressed mother-infant pairs at 2 months. Dev Psychol. 1990;26(1):15-23.

24. Pauli-Pott U, Darui A, Beckmann D. Infants with atopic dermatitis: maternal hopelessness, child-rearing attitudes and perceived infant temperament. Psychother Psychosom. 1999;68(1):39-45.

25. Absolon CM, Cottrell D, Eldridge SM, Glover MT. Psychological disturbance in atopic eczema: the extent of the problem in school-aged children. Br J Dermatol. 1997;137(2):241-245.

26. Goodman SH, Brogan D, Lynch ME, Fielding B. Social and emotional competence in children of depressed mothers. Child Dev. 1993;64(2):516-531.

27. Jaenicke C, Hammen C, Zupan B, et al. Cognitive vulnerability in children at risk for depression. J Abnorm Child Psychol. 1987;15(4): 559-572.

28. Dawson G, Frey K, Panagiotides H, Osterling J, Hessl D. Infants of depressed mothers exhibit atypical frontal brain activity: a replication and extension of previous findings. J Child Psychol Psychiatry. 1997;38(2):179-186.

29. Barankin B. Psychosocial effect of common skin diseases. Can Fam Physician. 2002;48:712-716.

30. Daud LR, Garralda ME, David TJ. Psychosocial adjustment in preschool children with atopic eczema. Arch Dis Child. 1993;69(6): 670-676.

31. Cramer P, Steinwert T. Thin is good, fat is bad: how early does it begin? J Appl Dev Psychol. 1998;19(3):429-451.

32. Magin P, Adams J, Heading G, Pond D, Smith W. Experiences of appearance-related teasing and bullying in skin diseases and their psychological sequelae: results of a qualitative study. Scand J Caring Sci. 2008;22(3):430-436.

33. Wittkowski A, Richards HL, Griffith CEM, Main CJ. The impact of psychological and clinical factors on quality of life in individuals with atopic dermatitis. J Psychosom Res. 2004;57(2):195-200.

34. Kunz B, Oranje AP, Labrèze L, Stalder JF, Ring J, Taieb A. Clinical validation and guidelines for the SCORAD index: consensus report of the European Task Force on Atopic Dermatitis. Dermatology. 1997; 195(1):10-19.

35. Williams HC, editor. Atopic Dermatitis. The Epidemiology, Causes and Prevention of Atopic Eczema. Cambridge: Cambridge University Press; 2000.

36. Ring J. Atopic Dermatitis: Eczema. Berlin: Springer; 2016.

37. Smith PK, Cowie H, Olafsson RF, et al. Definitions of bullying: a comparison of terms used, and age and gender differences, in a fourteen country international comparison. Child Dev. 2002;73(4): 1119-1133.

38. Magin P. Appearance-related bullying and skin disorders._Clin Dermatol. 2013;31(1):66-71.

39. Eccles J. The development of children ages 6-14. When School Is Out. 1999;9(2):30-44.

40. Duchesne AP, Dion J, Lalande D, et al. Body dissatisfaction and psychological distress in adolescents: is self-esteem a mediator? J Health Psychol. 2016. Epub 2016 Feb 29.

41. Finlay AY. The burden of atopic eczema. In: Ring J, Przybilla B, Ruzicka T, editors. Handbook of Atopic Eczema. 2nd ed. Berlin: Springer Science \& Business Media; 2006:31-36.
42. Brenninkmeijer EE, Legierse CM, Sillevis Smitt JH, Last BF, Grootenhuis MA, Bos JD. The course of patients with childhood atopic dermatitis. Pediatr Dermatol. 2009;26(1):14-22.

43. Saunes M, Smidesang I, Holmen TL, Johnsen R. Atopic dermatitis in adolescent boys is associated with greater psychological morbidity compared with girls of the same age: the Young-HUNT study. $\mathrm{Br} J$ Dermatol. 2007;156(2):283-288.

44. Chernyshov P. Dermatological quality of life instruments in children. G Ital Dermatol Venereol. 2013;148(3):277-285.

45. Lewis-Jones MS, Finlay AY. The Children's Dermatology Life Quality Index (CDLQI): initial validation and practical use. $\mathrm{Br} J$ Dermatol. 1995;132:942-949.

46. Shum KW, Lawton S, Williams HC, Docherty G, Jones J. The British Association of Dermatologists audit of atopic eczema management in secondary care. Phase 3: audit of service outcome. Br J Dermatol. 2000;142(4):721-727.

47. Aziah MS, Rosnah T, Mardziah A, Norzila MZ. Childhood atopic dermatitis: a measurement of quality of life and family impact. Med $J$ Malaysia. 2002;57(3):329-339.

48. Ben-Gashir MA, Seed PT, Hay RJ. Quality of life and disease severity are correlated in children with atopic dermatitis. $\mathrm{Br} J$ Dermatol. 2004;150(2):284-290.

49. Gånemo A, Svensson A, Lindberg M, Wahlgren CF. Quality of life in Swedish children with eczema. Acta Derm Venereol. 2007;87(4):345-349.

50. Kim DH, Li K, Seo SJ, et al. Quality of life and disease severity are correlated in patients with atopic dermatitis. J Korean Med Sci. 2012; 27(11):1327-1332.

51. Dertlioğlu SB, Cicek D, Balci DD, Halisdemir N. Dermatology life quality index scores in children with vitiligo: comparison with atopic dermatitis and healthy control subjects. Int J Dermatol. 2013;52(1):96-101.

52. Mozaffari H, Pourpak Z, Pourseyed S, et al. Quality of life in atopic dermatitis patients. J Microbiol Immunol Infect. 2007;40(3):260-264.

53. Slattery MJ, Essex MJ, Paletz EM, et al. Depression, anxiety, and dermatologic quality of life in adolescents with atopic dermatitis. $J$ Allergy Clin Immunol. 2011;128(3):668-671.

54. Bannink R, Pearce A, Hope S. Family income and young adolescents' perceived social position: associations with self-esteem and life satisfaction in the UK Millennium Cohort Study. Arch Dis Child. 2016. Epub 2016 Mar 8.

55. Camfferman D, Kennedy JD, Gold M, Martin AJ, Winwood P, Lushington K. Eczema, sleep, and behavior in children. J Clin Sleep Med. 2010;6(6):581-588.

56. Chamlin SL, Cella D, Frieden IJ, et al. Development of the Childhood Atopic Dermatitis Impact Scale: initial validation of a quality-of-life measure for young children with atopic dermatitis and their families. J Invest Dermatol. 2005;125(6):1106-1111.

57. Lewis-Jones MS, Finlay AY, Dykes PJ. The Infants' Dermatitis Quality of Life Index (IDQoL). Br J Dermatol. 2001;144(1):104-110.

58. Chernyshov PV, Jirakova A, Ho RC, et al. An international multicenter study on quality of life and family quality of life in children with atopic dermatitis. Indian J Dermatol Venereol Leprol. 2013;79(1):52-58.

59. Ricci G, Bendandi B, Bellini F, et al. Atopic dermatitis: quality of life of young Italian children and their families and correlation with severity score. Pediatr Allergy Immunol. 2007;18(3):245-249.

60. Chernyshov PV. May the gender of a parent influence assessment of health-related quality of life, family impact and severity of atopic dermatitis in children. Pediatr Dermatol. 2009(1);26:99-100.

61. Chernyshov PV. Gender differences in health-related and family quality of life in young children with atopic dermatitis. Int $J$ Dermatol. 2012;51(3):290-294.

62. Chernyshov P, Ho R, Monti F, Jirakova A, Velitchko S, Hercogova J, Neri E. Gender differences in self-assessed health-related quality of life in children with atopic dermatitis. J Clin Aesthet Dermatol. In press.

63. Haavet OR, Straand J, Saugstad OD, Grunfeld B. Illness and exposure to negative life experiences in adolescence: two sides of the same coin? A study of 15-year-olds in Oslo, Norway. Acta Paediatr. 2004;93(3):405-411. 
64. Chernyshov PV, Kaliuzhna LD, Reznikova AA, Basra MK. Comparison of the impairment of family quality of life assessed by disease-specific and dermatology-specific instruments in children with atopic dermatitis. J Eur Acad Dermatol Venereol. 2014;29(6):1221-1224.

65. Bockelbrink A, Heinrich J, Schäfer I, et al. Atopic eczema in children: another harmful sequel of divorce. Allergy. 2006;61(12):1397-1402.

66. Walker C, Papadopoulos L, Hussein M. Paediatric eczema and psychosocial morbidity: how does eczema interact with parents' illness beliefs? J Eur Acad Dermatol Venereol. 2007;21(1):63-67.

67. Chernyshov P, Jiráková A, Hercogová J. Comparative study of the quality of life of children with atopic dermatitis from Ukraine and the Czech Republic. J Eur Acad Dermatol Venereol. 2011;25:1483-1484.

68. Sartorius N. Stigmatized illnesses and health care. Croat Med J. 2007;48(3):396-397.

69. Staab D, von Rueden U, Kehrt R, et al. Evaluation of a parental training program for the management of childhood atopic dermatitis. Pediatr Allergy Immunol. 2002;13(2):84-90.

70. Gieler U, Köhnlein B, Schauer U, Freiling G, Stangier U. Counseling of parents with children with atopic dermatitis. Hautarzt. 1992;43(Suppl 11): S37-S42.

71. Weber MB, Fontes Neto Pde T, Prati C, et al. Improvement of pruritus and quality of life of children with atopic dermatitis and their families after joining support groups. $J$ Eur Acad Dermatol Venereol. 2008;22(8):992-997.
72. Ricci G, Bendandi B, Aiazzi R, Patrizi A, Masi M. Three years of Italian experience of an educational program for parents of young children affected by atopic dermatitis: improving knowledge produces lower anxiety levels in parents of children with atopic dermatitis. Pediatr Dermatol. 2009;26(1):1-5.

73. Grillo M, Gassner L, Marshman G, Dunn S, Hudson P. Pediatric atopic eczema: the impact of an educational intervention. Pediatr Dermatol. 2006;23(5):428-436.

74. Kondo Y, Nakajima Y, Komatsubara R, et al. Short-term efficacy of tacrolimus ointment and impact on quality of life. Pediatr Int. 2009; 51(3):385-389

75. Staab D, Kaufmann R, Bräutigam M, Wahn U; CASM981CDE04Study Group. Treatment of infants with atopic eczema with pimecrolimus cream 1\% improves parents' quality of life: a multicenter, randomized trial. Pediatr Allergy Immunol. 2005;16(6): 527-533.

76. Alzolibani AA. Impact of atopic dermatitis on the quality of life of Saudi children. Saudi Med J. 2014;35(4):391-396.

77. Ražnatović Djurović M, Janković J, Tomić Spirić V, Janković S. Health-related quality of life in children with moderate to severe atopic dermatitis. Acta Dermatovenerol Croat. 2015;23(3):178-184.

78. Alanne S, Nermes M, Soderlund R, Laitinen K. Quality of life in infants with atopic dermatitis and healthy infants: a follow-up from birth to 24 months. Acta Peadiatr. 2011;100(8):e65-e70.
Clinical, Cosmetic and Investigational Dermatology

\section{Publish your work in this journal}

Clinical, Cosmetic and Investigational Dermatology is an international, peer-reviewed, open access, online journal that focuses on the latest clinical and experimental research in all aspects of skin disease and cosmetic interventions. This journal is included on PubMed. The manuscript management system is completely online

\section{Dovepress}

and includes a very quick and fair peer-review system, which is all easy to use. Visit http://www.dovepress.com/testimonials.php to read rea quotes from published authors 